Wild, M., Silberfeld, C., Nightingale, B. (2015) 'More? Great? Childcare? - A discourse analysis of two recent social policy documents relating to the care and education of young children in England', International Journal of Early Years Education , 23 (3)

DOI: $\underline{\text { http://dx.doi.org/10.1080/09669760.2015.1079167 }}$

This document is the authors' Accepted Manuscript.

License: https://creativecommons.org/licenses/by-nc-nd/4.0

Available from RADAR: https://radar.brookes.ac.uk/radar/items/23849915-88a8-44e9-a842-41d5a2d6acdf/1/

Copyright (C) and Moral Rights are retained by the author(s) and/ or other copyright owners unless otherwise waived in a license stated or linked to above. A copy can be downloaded for personal non-commercial research or study, without prior permission or charge. This item cannot be reproduced or quoted extensively from without first obtaining permission in writing from the copyright holder(s). The content must not be changed in any way or sold commercially in any format or medium without the formal permission of the copyright holders. 


\title{
More? Great? Childcare? - A discourse analysis of two recent social policy documents relating to the care and education of young children in England.
}

\begin{abstract}
This paper considers the overt and covert discourses in two contemporary policy documents in England and Wales: Foundations for Quality (Department for Education (DfE), 2012) and More Great Childcare (MGC) (DfE, 2013) that advocated a number of significant changes to Early Years provision. It employs Critical Discourse Analysis (CDA) to ask questions about relationships between language and society, specifically how these are managed in policy documents. Drawing on Foucauldian analysis on the power behind the words and utilising Fairclough's (2010) CDA, indications of underlying values and assumptions, overt and covert agendas were explored. Findings suggest a significant shift in concepts of quality, professionalism and childcare which positions the child as an investment in the future as a strong feature of the discourse within MGC as well as an increase in top down frameworks. Both documents assert that quality and professionalism will only occur with top down regulation and inspection. They propose a consumer market based model of practice that has implications for professionalism of the workforce and quality of children's experiences.
\end{abstract}

Key words: Early Years, Quality, Provision, Workforce; Policy 


\section{Introduction}

It has been argued that since 2000, there has been a shifting emphasis from care to education in government policy in England (Elfer, 2007), which appears to show a move towards more prescribed and planned learning and education and away from the fundamental principles of caring relationships. Elfer (2007) suggests that the intimacy and spontaneity of the family like experience is becoming lost in the move towards more organised and controlled early childhood environments. Urban (2010, p2) argues that education for young children has changed from being meaningful and interactive to being 'decontextualized, technocratic practices imposed on both children and educators in many educational institutions'. According to Ball $(2003,216)$ this control can happen in relation to government policy in order to 'create the pre-conditions for various forms of 'privatization' and 'commodification' of core public services'. Ball $(2003,215)$ suggests that this can be done by embedding 'three interrelated policy technologies; the market, managerialism and performativity'. With complex educational reforms in the 1990s and devolvement of centralisation, markets and managers were given greater 'freedom' in relation to finance and human resource management. This changed the nature of what it was to be a teacher, both in identity and practice. The concept of performativity relates to contemporary moves to make individuals focus their practice on targets, outcomes and evaluations, which standardises and homogenises practice without taking into account the complexities of contextualised practice.

Urban (2010) and Lloyd and Hallet (2010) have also questioned how this shift in emphasis to outcome driven provision influences and impacts on early years practice and professionalism conflicting with practitioners views about their professional identity. Correspondingly, the change in status and roles of early childhood professionals and practitioners evolved and developed in response to the need for a graduate workforce, recognised by policy which developed under the New Labour government of 1997 (Lloyd and Hallet 2010). Subsequently the link between early years policy and the changing nature of professionalism at the micro level was demonstrated in Osgood's (2011) research into particular nursery contexts.

\section{Contemporary Early Childhood Policy in England}

More Great Childcare (DfE, 2013) and the Foundations for Quality (Nutbrown, DfE, 2012) were two policy documents, pertaining to Early Years provision in England and Wales. Both documents focused in particular on the nature of the early years workforce as a key component in determining 'quality' provision. The Nutbrown Review (DfE, 2012) was commissioned in response to other policy reports which highlighted that successful early intervention was dependent on high quality provision and high quality staff. The review identified disparities between similarly highly qualified staff. Both primary teachers (QTS) and early years professionals (EYP) were graduates. Staff with Qualified Teacher Status (QTS), the highest qualification for those working with children aged 3-7 years, had a career 
structure and a regulated pay-scale. However, those with Early Years Professional Status (EYPS), who had been trained to work with children aged 0-5 years, did not. They did not have a similar status recognition to those with QTS because EYP was not considered to be a qualification, nor despite sometimes being suggested as equivalent, did EYP Status, entitle the holder to the same benefits of career and pay provided by QTS status.

The Nutbrown Review (DfE 2012) proposed a solution to this disparity by the introduction of a specialist teacher for children aged 0-7 years. It was potentially a way forward for a professional route to an integrated care and education qualification that could have similar pay, status and conditions to someone with QTS. This was one of 19, generally welcomed, recommendations from the review. However, in 'More Great Childcare: Raising quality and giving parents more choice' (DfE 2013), the government's response to The Nutbrown Review, only 5 of the 19 recommendations were taken forward, and did not include the specialist teacher. In contrast to the Nutbrown Review (DfE 2012), there was an emphasis on a greater quality of choice of childcare provision for parents rather than a greater quality of the provision itself. There were several new proposals in More Great Childcare (DfE 2013), including changes to ratios of numbers of staff to children, and new structures of inspection and regulation.

Both reports stated how important it was to have a well-qualified workforce providing high quality experiences for babies and young children, in order to meet their current needs and prepare them for their futures. Whereas More Great Childcare (DfE 2013 4) concentrated on the need to build a strong professional workforce, Foundations for Quality (DfE 2012,3) emphasised the need to ensure professional and pedagogic development in order for practitioners to develop their understanding of how and why they could support and extend children's learning opportunities.

Although both documents appeared to complement each other in their vision for quality, childcare and education, it was apparent that the recommendations from Foundations for Quality (DfE 2012) were only partially addressed in More Great Childcare (DfE 2013). It also appeared that there were very differing approaches to achieving these quality initiatives.

In order to explore this seeming disconnect in more depth, this research attempted to analyse the language used within the two government publications, and explore any perceived similarities and differences. In doing so there is a resonance with the seminal work of Foucault (1972) who drew attention to the power of words as an indicator of the complex interplay between language and ideology and the power they reciprocally impart to one another. This concept has been further developed by Fairclough (1992, 3-4), who argued that:

\section{'Discourses do not just reflect or represent social entities and relations, they construct or constitute them.'}

In later and more recent expositions of his thinking, Fairclough has continued to draw specific attention to discourse analysis within the policy arena (Fairclough, 2010; Fairclough and Fairclough 2012). Critical Discourse Analysis (CDA) has been used by educational 
researchers to ask questions about relationships between language and society, specifically how these are managed in policy documents. It is worth noting that Fairclough's recent elaborations of CDA point out that the systematic and descriptive analysis of text is but part of the critical discourse analysis, which can only be truly realized in relation to wider aspects of the social processes and context. Nevertheless the systemic analysis of text can offer a useful tool to raise questions about relationships between language and society, specifically how these are managed in policy documents including educational policy (Baker 2006; Baker 2010).

The Nutbrown Review (DfE 2012) and More Great Childcare (DfE 2013) purport to have similar agendas. It is only by analysing these documents in relation to the context in which they are used that differences may emerge. Philosophical values and political agendas are not necessarily explicit but may instead be operating beneath the surface of the words and may be revealed in a more systematic analysis of texts looking at the juxtaposition and co alignment, or concordances, of words as well as the frequency or indeed absence of certain words (Baker, 2006). Close textual analysis of the two documents selected could thus offer some discrete insights in to the broader policy debates and agendas operating within the policy context of the English Early Years sector.

\section{Methodology}

A particular aim of the research was to explore underlying values and assumptions, as well as overt and covert agendas, by systematically analysing the frequency of key words in both documents in order to be able to carry out a critical discourse analysis using Fairclough's theoretical framework. The approach which was utilised is based on the work of Anthony (2013a), and Baker (2010) which identified a number of linguistic aspects that can illuminate meanings and patterns within textual analysis. These can include:

- Frequency, which ranks the frequencies with which particular words or phrases occur.

- Collocation, which identifies words that typically occur alongside one another. These may be best understood when considered alongside concordance information.

- Concordance, which lists the occurrences of particular words or terms within their immediate linguistic context. Thus it is similar to a frequency count and incorporates collocation but enables greater contextual interrogation as patterns of words and phrases can be more readily discerned.

- Keywords, which factor in lexically common words and word groupings so as to identify words that are more common than might be expected on the basis of other known texts within the field.

- Dispersion, which is the extent to which a word occurs in clusters within a corpus or is more evenly distributed.

The Antconc Tool (Anthony 2013b), is a computer programme designed to interrogate text within the parameters listed above. Drawing on extant research into discourse analysis 
techniques (Anthony 2009; Anthony 2013a) it is one of seven such tools highlighted within academic synopses of the field (Baker 2010).

For the purposes of analyzing the Nutbrown Review (NR) and More Great Childcare (MGC) the following combination of linguistic aspects were considered:

1. A simple word frequency listing was generated for each document.

2. Having generated a list of frequencies for each document, common grammatical constructs such as the definite/ indefinite article, conjunctions, prepositions etc. were excluded and the lists were scrutinized for nouns of relevance to the field of Early Years, drawing on expert opinion through the Early Childhood Studies Degree Network in the UK. This enabled the identification of a number of key thematic groupings of words that are pertinent to the field of Early Years and the policy context of the two documents under consideration.

3. Within these themes the frequency and relative ranking of usages of the selected keywords and their derivative forms were analysed to identify their respective frequency of use in NR compared to MGC and their relative ranking in order of frequency in each document.

4. For each document only words occurring in the top placed 150 words were sampled.

5. Concordances, incorporating collocation information of selected keywords, in NR and MGC were compared. Concordance plots were generated to establish that there were no unusual dispersal patterns.

6. Both documents were then compared to establish words that have particularly noticeable differential occurrences or words that do not appear as frequently as might be expected in light of the Early Childhood context.

The key ethical consideration was to take seriously the responsibility to be truthful and as objective as possible, and being objective by seeking to eliminate bias when engaged in a critique of policy documents. This was facilitated by identifying the word frequencies in each of the documents before applying an interpretation.

A simple frequency analysis of particular words excludes any contextual analysis of the sense in which these words have been utilized (Tenorio 2011) but this was mitigated to an extent by the consideration of the colocation of terms. CDA is sometimes criticised on the grounds of a lack of process between generating the frequency of words and their subsequent interpretation (Breeze 2011). This was addressed by developing a thematic grouping of frequencies within three overarching categories:

\section{Theme 1: Staff-related Terminology}


child-minder(s); experiences; knowledge; leadership; practitioner(s); professional(s) ; practice; qualification(s); qualified; skills; staff; support; teacher(s); training; understanding; workforce;

\section{Theme 2: Nature of Provision}

agency ; childminder(s); choice: flexibility; Inspection; Nursery(ies); Ofsted; Providers; provision; Quality; ratios; requirements; school(s) ; settings;

\section{Theme 3: Children Families and Development}

babies; care; childcare; child(ren);development; education; family(ies); learning; needs; parents; play.

\section{Findings}

For each of the three themes identified above the frequencies of words are presented in tables to show both the ranking of that word in the frequency tally for that document, along with the number of times it appears in the document. Although the documents are not of equal length the inclusion of the word ranking within each document indicates its relative significance within its own document and this can be compared across the documents, whereas the raw score of how many times it appears is less directly comparable. Nonetheless the raw score does give some indication of its prevalence and dispersal throughout the document within which it occurs. Exemplars of common patterns of concordances for selected keywords are then presented.

\section{Theme 1: Staff-related terminology}

\section{TABLE 1 HERE}

\section{Concordance from Theme 1: Qualifications}

From the list of staff-related terminology using word ranking and word occurrence it was possible to identify a common high ranking theme around staff qualifications in each of the documents. The following extracts are examples of the way in which this concordance was used.

\section{Nutbrown}

'We need a rigorous set of qualifications in place to ensure a competent and confident workforce'

'a worrying decline of confidence in early years qualifications and to a lowering of what we can confidently expect' 
'Dramatic growth in the number of early years qualifications from around three in 1980 to many hundreds today;'

$M G C$

'capable workforce, with more rigorous training and qualifications, led by a growing group of Early Years Teachers;'

'the quality of the workforce and the qualifications on offer at the moment are not good enough'

'exacerbated by the proliferation of early years qualifications which has occurred since the 1970s'

'many of which lack rigour and depth. We will improve early years qualifications so that parents and providers can have greater confidence'

\section{Theme 2: Nature of provision}

\section{TABLE 2 HERE}

\section{Concordance from Theme 2: Quality}

Within these word rankings it could be seen that the nominal type of provision that was foregrounded differed in the two reports. The Nutbrown Report tended to use the more generic term "settings" whereas More Great Childcare utilised language that highlighted the form of provision and tended to privilege the notion of "providers" and more frequently referred to schools, nurseries and child minders. Beyond the nominal descriptors both reports noted a focus on "quality". Therefore extracts from the documents relating to the quality of settings and provision were identified.

\section{Nutbrown}

Learning begins from birth, and high quality early education and care has the potential to make an important and positive impact on the learning, development and wellbeing of babies and young children, in their daily lives and the longer term.

Desire to give those children high quality experiences which enhance their lives and learning

$M G C$

Raising the status and quality of the workforce

Freeing high quality providers to offer more places

Expect childcare to be safe and of good quality, because high quality childcare promotes children's development in the early years

\section{Theme 3: Children Families and Development}




\section{TABLE 3 HERE}

\section{Concordance from Theme 3: Children \& Development}

It was not possible to identify collocation between all key words in the documents. Although the word babies and families generated a number of occurrences in NR, there were none in the top 150 occurrences in MGC. Conversely references to parents in MGC did not appear in the first 150 occurrences in NR. Therefore, this concordance focuses on the extracts relating to children and development.

\section{Nutbrown}

'form an understanding of each individual child, applying what they know about how children develop'

'is part of fully understanding child development and fostering independent and enquiring minds'

$M G C$

'crucial to the development of babies and young children as the foundation for their future success at school'

'by helping parents back to work and readying children for school and, eventually, employment'

\section{Summary of Concordance Themes}

Although this research only looked at aspects of concordance, the findings revealed more differences than similarities. Even where there were similarities in frequency and ranking, there were differences in context and meaning of the words. For example, in MGC (DfE 2013) the reference to staff was more aligned to leadership, whereas in the Nutbrown Review (DfE 2102) there was a greater emphasis on professionalism. Similarly, in MGC the word quality emphasised choice and availability of childcare and education (commodification), whereas the Nutbrown Review emphasised the quality of the child's experience of that care and education (experiential). The contrast between these approaches to quality could be explained by differing political and ideological viewpoints. Differing viewpoints can also be seen in the way in which children and families, and their needs are positioned. In MCG there is a focus on the standardisation and outcomes of childcare and education, of helping parents back to work, and getting children ready for school. By contrast, the Nutbrown Review focuses on the process of care and education for the child, in order to develop and foster independent and enquiring minds.

Of note within both documents was the low priority given to certain issues such as relationships, children's wellbeing, culture, diversity and special needs. For example in 
MGC, although high priority was given to school, teachers, and inspection of provision, there was no mention of babies specifically, and no reference to play as being an essential part of children's learning and development. Some of these issues of low priority in both documents will be discussed further in the next section.

\section{Discussion}

This research has demonstrated both similarities and differences of word frequencies and ranking in MGC and the Nutbrown Review using a CDA approach. On further exploration it could be seen that similar words did not necessarily have similar meanings. This was not unexpected because, from a Foucauldian perspective, although discourse can generate knowledge and truth, this type of discourse operates in powerful political and ideological systems within society which restrict how it can be interpreted (Foucault 1972). Even when there appears to be commonality

...it hides beneath what appears, and secretly duplicates it, because each discourse contains the power to say something other than what it actually says, and thus to embrace a plurality of meanings. (Foucault 1972, 118)

Discourse communicates knowledge not only about the intended meaning of the language, but also about those who put forward the discourse. Therefore, the way in which discourse is written will reflect the way in which the discourse is intended to be acted upon.

\section{Staff related terminology}

Within the first concordance theme there was a clear distinction in the way that the words related to qualifications were used. Although the words qualified and training had a similar ranking in both documents (see Table 1), the contexts of occurrences of these words were very different. Both reports recognise that there is an over proliferation of early years qualifications. However in MGC (DfE, 2013) the words qualified and training emphasised the need to have more standardised training and qualifications for the early childhood workforce. The Nutbrown Review also wanted more rigour within training but emphasised the need to have a 'confident and competent workforce' (DfE, 2012, p6) who had different levels of skills and abilities. In contrast MGC (DfE, 2013), placed a greater emphasis on the needs of parents and providers to have greater confidence in the early years workforce. The MGC (DfE, 2013) proposed that the early years workforce would be led by a group of early years teachers who would be expected to lead and take responsibility for the provision. However these early years teachers would not have the same level of pay or conditions as newly qualified teachers (NQT's).

Both documents stress the importance of having a competent workforce. A competent practitioner is viewed as someone who has a recognised qualification and experience of working with young children. This is a very broad framework because neither the specific 
qualifications are referred to, nor the length or quality of the experience. For example Nutbrown (2012) states 'We need a rigorous set of qualifications in place to ensure a competent and confident workforce' and MGC (2013) suggests the need for a 'capable workforce, with more rigorous training and qualifications, led by a growing group of Early Years Teachers'. MGC refers to the recently introduced Early Years Teacher (EYT) as leading and taking responsibility. This is not the same qualification as those who have undergone QTS teacher training. The latter has a higher status, better pay and conditions, and established support networks for professional development. An EYT would be able to work in a variety of early years settings but would not have the same status pay or conditions as a practitioner with QTS. Similarly it is less likely that someone who has Qualified Teacher Status (QTS) would be working with Foundation Stage children in early childhood settings which are organisations which aim to make a profit, where the pay and conditions may not reflect their status or expectations. This is not to say those with lower status qualifications are not competent, but the emphasis of these types of qualifications is on the functional practical role rather than the professional developmental role. Since the introduction of the EYFS settings have become more prescriptive in their approach to early childhood care and education in their attempt to meet all the required learning outcomes. This is particularly so in settings where there is top down management and little autonomy for practitioners (Silberfeld and Horsley 2013), and found to be common within bureaucratic models of leadership in which "decisions and behaviour are governed by rules and regulations rather than personal initiative' (Bush 2011, 48). In such bureaucracies Bush suggests that 'the bureaucracy itself may become the raison d'être of the organisation rather than subordinated to educational aims' (ibid, 49). Ideological differences therefore suggest that one tends towards prescriptive practice and outcome and the other towards teaching and learning as a creative and developmental process. Although both are driven by similar standards and accountability, responsibility for professional development is expressed very differently in the government documentation.

\section{Qualifications}

There is an argument within both policy documents that there are too many qualifications many of which lack the necessary rigour. Whereas Nutbrown (2012) suggests that there has been some dilution and 'a worrying decline' in the confidence and competence of early years practitioners because of the range of qualifications, in MGC (2013) which is also concerned about the proliferation of qualifications, their concern is not so much with the dilution but with ensuring some mechanism of standardisation. The Nutbrown Review suggests that there is a need to ensure practitioners are qualified to a high level whereas MGC suggests that the qualifications can be improved in quality by reducing the number and standardising the content and outcomes. There is also an emphasis on improving early years qualifications 'so that parents and providers can have greater confidence' (MGC 2013, 6). This is in contrast to the Nutbrown Review which focuses on the improvement of qualifications to further prevent the 'decline' of practitioners' confidence (Nutbrown 2012, 17). 
There is an irony in governmental concerns about the proliferation of qualifications as this has come about through government policy which de-regulated early childhood qualification providers in the 1980's and has continued to be the policy of subsequent governments. Deregulation opened the market to private organisations who offered early childhood qualifications at increasingly competitive rates. Franchising became popular with many Awarding Bodies which was instrumental in the process of this proliferation. At the same time National Vocational Qualifications (NVQ), which were introduced in the late 1980s/early 1990s gave practitioners the opportunity to gain qualifications in the workplace, which would previously been inaccessible. Behind the workplace qualifications initiative was an attempt to improve the quality of provision, however the quality of the provision itself, and those who assessed the practice, differed greatly between settings.

\section{Nature of Provision}

In addition to the increase in qualifications there has also been an increase the type, range and number of early years providers, both in the state and independent sector. This has been in response to national socio-economic developments within society. It is not unusual for both parents in a family, and single parents to be working which has increased the need for childcare and education provision. This need has opened up profitable business opportunities within the childcare market. Although all settings are regulated and inspected there is no requirement for an entrepreneur to have any knowledge, understanding or skills of working with young children. There is also no impetus to employ the most highly qualified, and usually the most expensive, practitioners. Since 1997 there has been a steady increase in forprofit provision, with a 70\% increase from 2002 - 2008, which has now become the major provider for childcare of the under threes (Penn 2011). In addition $80 \%$ of all childcare and $40 \%$ of early education is now provided by this sector. Although many providers are run by individual entrepreneurs, it has been estimated by Penn (2013) that $10 \%$ of the childcare and education market is being provided by non UK based corporate companies. Lloyd (2012) suggests that this market approach encourages 'business efficiency' and a 'balance between supply and demand', whilst at the same time 'extending consumer choice'. This market approach seems to focus more on the quality of cost effective provision than quality of learning provision for the children.

\section{Quality}

The use of the word quality in both reports relates to the nature of early childhood provision. It also refers to the quality of those who work with young children. The Nutbrown Review (DfE 2012) stresses the importance of training the early years workforce in high quality settings and supported by highly qualified staff. MGC (DfE 2013) also proposed that improving the quality of the early childhood workforce was important but did not suggest how this could be achieved. The report's emphasis was that a high quality workforce would free 'high quality' providers to offer a higher number of places in settings, thus allowing a 
market solution to the increased need for available early childhood provision. Although MGC (DfE 2013) recognises that quality childcare and education promotes children's development, its emphasis on standardisation and outcome relies more on the immediacy of how the care is provided in the short term, rather than the potential for quality experiences to have a long term impact on the learning and development of the child. There is an emphasis in Nutbrown (DfE 2012) on quality provision being an investment in the child's future wellbeing which contrasts with MGC's (DfE 2013) emphasis on the economic investment. Historically the early years workforce has been predominantly female and low paid. Despite the drive in recent years towards a more highly qualified workforce, pay and conditions have not reflected these improvements (Miller 2008). Several years ago Moss (2003) put forward an interesting dilemma which may need to be addressed by future governments. He suggested that as women become better educated they may seek wider employment opportunities with better pay and conditions, rather than remaining in the early years workforce. There is nowhere within either document which considers this dilemma of gender inequity, pay and conditions.

\section{Children, Families and Development}

Within both policy documents there is acknowledgement that children's learning experiences should be of high quality. However the concept of what can be a high quality experience does not include the positioning of the child either within the family or as an individual in their own right (Lloyd 2008) or indeed what constitutes the needs of the child and whether these should be future oriented in terms of preparedness for school and eventual employability. There is also some ambivalence in both documents as to whether the needs of the child, the family or the state take precedence in the provision of childcare and education. Although there is a need to balance the interests and needs of children with the needs of the family and state, unless children experience high quality provision which meets their needs in the here and now, their 'becoming' may be adversely affected and it may affect their ability to achieve their potential.

The concepts of learning and development in the Nutbrown Review (2012) contrast with the concepts of learning and development in MGC (2013). Although both emphasise the importance of the development of, and learning experiences for, children for their long term wellbeing and readiness for school, there is a difference in perception of how this can be achieved. Nutbrown (2012) suggests that quality learning nurtures children and facilitates the development of 'independent and enquiring minds', whereas MGC (2013) suggests that quality learning is a social investment which facilitates specific learning outcomes that are the 'foundation for their future success at school'. Both suggest the need for 'schoolification' and preparation for the future (Nutbrown Review 2012, 8; MGC 2013, 4).

\section{Perceived Omissions}


In both documents there are omissions which seem striking in the context of designing quality experiences for young children. There is a lack of focus on the importance of the relationships which are developed in childhood, and how these can affect learning and development and future wellbeing. Research evidence demonstrates that children's need for emotional warmth in the early years is pivotal to their development and wellbeing (Oates 2007). Children need to form strong, mutual attachments with caregivers for their physical and emotional development. Such attachments are seen as a universal right for young children that enable them to 'construct a personal identity and acquire culturally valued skills, knowledge and behaviours' (UNCRC 2005, 8).

\section{Reflecting on the Methodology}

CDA is recognised as encompassing a hegemony of theoretical perspectives which aims to systematically investigate how power relationships ideologically shape what happens in society through practices and discourse (Fairclough 2010). It is inevitable that government policy will be influenced by political ideology, by its very nature. However, this influence may be well-hidden by the way in which policy documents are written. In both the Nutbrown Review and More Great Childcare the messages which come across highlight the importance of high quality care for young children. By systematically interrogating the language within the documents different interpretation of similar words emerged based on the frequency and context of the ways in which they were used. Although there was awareness of the need to be as objective and truthful as possible when analysing the frequencies and concordances, we were also aware that our interpretations of the discourse were influenced by our own experiences and ideologies. This has been highlighted for many years by critics of CDA who have suggested that such a method of analysing linguistic data can be used to confirm an interpretation already arrived at concerning the meaning of a text (Tenorio 2011). Fairclough (2010) has refuted these claims by his assertion that CDA is much more to do with questioning the purposes and intentions of the text, rather than the texts being interpreted in one particular ideological manner. Using Fairclough's theoretical framework we were able to explore the discourse within both policy documents, which, in turn, heightened our awareness of the complex positionality within them.

This research has raised some important questions relating to the relationship between language and political ideology in contemporary policy documents. It also gives some insight into the way in which discourse can reproduce social and political ideology.

\section{Conclusion}

There appeared to be a change of tone between the language and concepts of the Nutbrown Review (DfE 2012) and the reply of More Great Childcare (DfE 2013). This may be because those who contributed to the Nutbrown Review Foundations for Quality (DfE 2012) came from a broad range of early childhood care and education professionals and organisations, whereas More Great Childcare (DfE 2013) was written by the Department for Education, from a particular political and ideological perspective. Initially it appears that they 
have a similar vision because they have similar rationales. The rationale in Foundations for Quality as put forward by Nutbrown focuses on the need to have high quality provision because of its importance in meeting the learning needs and wellbeing of young children, which in turn will have long term consequences for their future lives (Nutbrown, DfE 2012). There was a similar rationale for More Great Childcare (DfE 2013) with the addition of affordability of provision for working parents.

However, it could be further argued that the ideological emphasis in MGC (DfE 2013) re-positions the importance of the early years by focusing on de-regulation, and the supply and demand of provision. It also opens up the market to child care providers and potentially allows them to employ less costly staff who may lack the depth and breadth of knowledge and experience of those who are more qualified which can impact on the quality of provision for children and families. Early Years teachers are not the graduate-led early childhood workforce with the parity and status of other qualified teachers within the education sector, as envisioned by those campaigning for an early years professional or pedagogue.

This research has highlighted the way in which similar words and concepts can be semantically very different, not only in the way that they are applied, but also in the way they are used politically and ideologically. Although one would expect policy documents to reflect the views, values and ideology of whichever government, individual or organisation is driving policy, the nuances of difference are not necessarily explicit. By analysing the frequency of key words in the Nutbrown Review and More Great Childcare, using the Antconc Tool, this approach to CDA has uncovered some of the differing values and assumptions which may underpin these policy documents. Whether or not this is related to different political agendas of those who wrote these documents is unclear. However, they do originate from different sources and this does seem to be reflected in the focus and tenor of the reports. Although the Government commissioned the Nutbrown Report, those who were engaged in the review did not form part of the Government. In contrast, More Great Childcare had direct Government input into the document, which reflects the Governments political agenda and in exploring perceived similarities and differences using CDA it became evident that there has been a distinct shift in the way that care and education for children has been more marketised and commodified, with an emphasis on educational outcomes rather than relational processes.

\section{Acknowledgements}

This article is based on a paper presented to the EECERA Conference (Tallinn, Aug 2013), with grateful acknowledgement of contributions from Pamela Calder, Caroline Leeson and Martin Needham of the Early Childhood Studies Degree Network in the UK. 


\section{References}

Anthony, L.2009. Issues in the Design and Development of Software Tools for Corpus Studies: The Case for Collaboration. In Contemporary Corpus Linguistics, edited by P. Baker, 87-104. London: Continuum Press.

Anthony, L. 2013a. A Critical Look at Software Tools in Corpus Linguistics. Linguistics Research 30 (2): 141-161.

Anthony, L. 2013b. AntConc 3.2.4w Programme

http://www.antlab.sci.waseda.ac.jp/antconc index.html.

Baker, P. 2006. Using Corpora in Discourse Analysis. London: Continuum International.

Baker, P. 2010. Sociolinguistics and Corpus Linguistics. Edinburgh: Edinburgh University Press.

Ball, S. J. 2003. The Teacher's Soul and the Terrors of Performativity. Journal of Education Policy 18 (2): 215-228.

Breeze, R. 2011. Critical Discourse Analysis and its Critics. Pragmatics 21 (4): 493-525.

Bush, T. 2011. Succession Planning In England: New Leaders and New Forms of Leadership. School Leadership and Management 31 (3): 181-198.

Department for Education. 2013. More Great Childcare: Raising Quality and Giving Parents More Choice. DFE-00002-2013.

https://www.gov.uk/government/uploads/system/uploads/attachment_data/file/219660/More 20Great_20Childcare_20v2.pdf.

Department for Education. 2012. The Nutbrown Review: Foundations for Quality: The Independent Review of Early Education and Childcare Qualifications. DFE-00068 2012 https://www.gov.uk/government/uploads/system/uploads/attachment_data/file/175463/Nutbr own-Review.pdf.

Elfer, P. 2007. What are Nurseries For?: The Concept of Primary Task and its Application in Differentiating Roles and Tasks in Nurseries. Journal of Early Childhood Research 5 (2): 169-188.

Fairclough, N. 1992. Discourse and Social Change. Cambridge: Polity Press.

Fairclough, N. 2010. Critical Discourse Analysis: The Critical Study of Language. Harlow: Pearson Education Ltd.

Fairclough, I., and N. Fairclough. 2012. Political Discourse Analysis. A Method for Advanced Students. London: Routledge.

Foucault, M. 1972. The Archaeology of Knowledge and Discourse on Language. London: Tavistock. 
Lloyd, E. 2008. The Interface between Childcare, Family Support and Child Poverty Strategies under New Labour: Tensions and Contradictions. Social Policy and Society 7 (4): 479-494.

Lloyd, E. 2012. The Marketization of Early Years Education and Childcare in England. In Policy Issues in the Early Years, edited by L. Miller, and D. Hevey, 107-122. London. Sage.

Lloyd, E., and E. Hallet. 2010. Professionalising the Early Childhood Workforce in England: Work in Progress or Missed Opportunity? Contemporary Issues in Early Childhood 11 (1): 75-88.

Miller, L. 2008. Developing Professionalism within a Regulatory Framework in England: Challenges and Possibilities. European Early Childhood Education Research Journal 16 (2): $255-268$.

Moss, P. 2003. Beyond Caring: The Case for Reforming the Childcare and Early Years Workforce. London: Daycare Trust.

Oates, J, ed. 2007. Attachment Relationships: Quality of Care for Young Children. Milton Keynes: Open University, and The Hague: Bernard van Leer Foundation.

Osgood, J. 2011. Narratives from the Nursery: Negotiating Professional Identities in Early Childhood. London: Routledge.

Penn, H. 2011. Gambling on the Market: The Role of For-Profit Provision in Early Childhood Education and Care. Journal of Early Childhood Research 9 (2): 150-161.

Penn, H. 2013. Childcare Markets: do they Work? In Childcare Markets: Can They Deliver an Equitable Service?, edited by E. Lloyd, and H. Penn, 19-43. Bristol: Policy Press.

Silberfeld, C.H., and K. Horsley. 2013. The Early Years Foundation Stage Curriculum in England: A Missed Opportunity?, In The Early Years Curriculum: The UK Context and Beyond, edited by L. Ang, 12-32. Harlow: Pearson.

Tenorio, E.H. 2011. Critical Discourse Analysis: An Overview. Nordic Journal of English Studies 10 (1): 183-210.

Urban, M. 2010. Rethinking Professionalism in Early Childhood: Untested Feasibilities and Critical Ecologies. Contemporary Issues in Early Childhood 11 (1): 1-7.

United Nations Committee on the Rights of the Child, United Nations Children's Fund, and Bernard Van Leer Foundation. 2005. A Guide to General Comment 7: Implementing Child Rights in Early Childhood. The Hague: Bernard Van Leer Foundation. http://www.unicef.org/earlychildhood/files/Guide_to_GC7.pdf 


\section{TABLES}

Table 1: Staff- related terminology: word ranking \& word occurrence

\begin{tabular}{|l|l|l|l|l|}
\hline \multirow{2}{*}{} & \multicolumn{2}{|l|}{ Nutbrown } & \multicolumn{2}{l|}{$\begin{array}{l}\text { More } \\
\text { Great Childcare }\end{array}$} \\
\hline Word & $\begin{array}{l}\text { Ranking in } \\
\text { document }\end{array}$ & $\begin{array}{l}\text { No. of } \\
\text { occurrences }\end{array}$ & $\begin{array}{l}\text { Ranking in } \\
\text { document }\end{array}$ & $\begin{array}{l}\text { No. of } \\
\text { occurrences }\end{array}$ \\
\hline qualification & 19 & 153 & & \\
\hline qualifications & 50 & 75 & 53 & 41 \\
\hline qualified & 79 & 50 & 76 & 29 \\
\hline training & 68 & 56 & 68 & 33 \\
\hline staff & 33 & 98 & 20 & 98 \\
\hline Practitioners & 52 & 72 & & \\
\hline Professional & 137 & 30 & & \\
\hline workforce & 75 & 51 & 140 & 18 \\
\hline childminders & & & 27 & 71 \\
\hline childminder & & & 84 & 26 \\
\hline Childminders & & & 147 & 16 \\
\hline teacher & & & 129 & 19 \\
\hline teachers & & & 130 & 19 \\
\hline practice & 58 & 62 & 144 & 17 \\
\hline support & 56 & 67 & & \\
\hline skills & 80 & 50 & & \\
\hline knowledge & 82 & 47 & & \\
\hline understanding & 88 & 43 & & \\
\hline experience & 94 & 41 & & \\
\hline leadership & 145 & 28 & & \\
\hline & & & & \\
\hline
\end{tabular}

$N B$ : where a row is blank this indicates that the word was not in the top 150 ranked words in that document 
Table 2: Nature of provision: word ranking \& word occurrence

\begin{tabular}{|c|c|c|c|c|}
\hline \multirow[b]{2}{*}{ Word } & \multicolumn{2}{|c|}{ Nutbrown Review } & \multicolumn{2}{|c|}{$\begin{array}{l}\text { More Great } \\
\text { Childcare }\end{array}$} \\
\hline & $\begin{array}{l}\text { Ranking } \\
\text { in } \\
\text { document }\end{array}$ & $\begin{array}{l}\text { No. of } \\
\text { occurrences }\end{array}$ & $\begin{array}{l}\text { Ranking in } \\
\text { document }\end{array}$ & $\begin{array}{l}\text { No. of } \\
\text { occurrences }\end{array}$ \\
\hline settings & 48 & 76 & & \\
\hline providers & & & 23 & 91 \\
\hline provision & & & 72 & 30 \\
\hline nurseries & & & 119 & 20 \\
\hline Nursery & & & 127 & 19 \\
\hline school & & & 54 & 41 \\
\hline schools & & & 77 & 29 \\
\hline agency & & & 82 & 27 \\
\hline quality & 42 & 82 & 10 & 130 \\
\hline Ofsted & & & 33 & 65 \\
\hline inspection & & & 50 & 42 \\
\hline requirements & & & 107 & 22 \\
\hline ratios & & & 61 & 38 \\
\hline France & & & 91 & 25 \\
\hline flexibility & & & 95 & 24 \\
\hline choice & & & 122 & 19 \\
\hline
\end{tabular}

$N B$ where a row is blank this indicates that word was not in the top 150 ranked words in that document 
Table 3: Children, families and development: word ranking \& word occurrence

\begin{tabular}{|c|c|c|c|c|}
\hline & Nutbrown & Review & \multicolumn{2}{|c|}{$\begin{array}{l}\text { More Great } \\
\text { Childcare }\end{array}$} \\
\hline Word & $\begin{array}{l}\text { Ranking in } \\
\text { document }\end{array}$ & $\begin{array}{l}\text { No. of } \\
\text { occurrence } \\
\text { s }\end{array}$ & $\begin{array}{l}\text { Ranking in } \\
\text { document }\end{array}$ & $\begin{array}{l}\text { No. of } \\
\text { occurrences }\end{array}$ \\
\hline children & 23 & 141 & 9 & 163 \\
\hline child & 84 & 44 & 65 & 36 \\
\hline babies & 132 & 31 & & \\
\hline families & 144 & 28 & & \\
\hline parents & & & 38 & 60 \\
\hline development & 46 & 76 & 90 & 25 \\
\hline needs & 146 & 27 & & \\
\hline education & 47 & 76 & 32 & 65 \\
\hline Education & & & 148 & 16 \\
\hline childcare & & & 37 & 62 \\
\hline care & & & 56 & 40 \\
\hline learning & 77 & 50 & & \\
\hline play & 131 & 32 & & \\
\hline
\end{tabular}

$N B$ where a row is blank this indicates that word was not in the top 150 ranked words in that document 


\title{
More? Great? Childcare? - A discourse analysis of two recent social policy documents relating to the care and education of young children in England.
}

\begin{abstract}
This paper considers the overt and covert discourses in two contemporary policy documents in England and Wales: Foundations for Quality (Department for Education (DfE), 2012) and More Great Childcare (MGC) (DfE, 2013) that advocated a number of significant changes to Early Years provision. It employs Critical Discourse Analysis (CDA) to ask questions about relationships between language and society, specifically how these are managed in policy documents. Drawing on Foucauldian analysis on the power behind the words and utilising Fairclough's (2010) CDA, indications of underlying values and assumptions, overt and covert agendas were explored. Findings suggest a significant shift in concepts of quality, professionalism and childcare which positions the child as an investment in the future as a strong feature of the discourse within MGC as well as an increase in top down frameworks. Both documents assert that quality and professionalism will only occur with top down regulation and inspection. They propose a consumer market based model of practice that has implications for professionalism of the workforce and quality of children's experiences.
\end{abstract}

Key words: Early Years, Quality, Provision, Workforce; Policy 


\section{Introduction}

It has been argued that since 2000, there has been a shifting emphasis from care to education in government policy in England (Elfer, 2007), which appears to show a move towards more prescribed and planned learning and education and away from the fundamental principles of caring relationships. Elfer (2007) suggests that the intimacy and spontaneity of the family like experience is becoming lost in the move towards more organised and controlled early childhood environments. Urban (2010, p2) argues that education for young children has changed from being meaningful and interactive to being 'decontextualized, technocratic practices imposed on both children and educators in many educational institutions'. According to Ball $(2003,216)$ this control can happen in relation to government policy in order to 'create the pre-conditions for various forms of 'privatization' and 'commodification' of core public services'. Ball $(2003,215)$ suggests that this can be done by embedding 'three interrelated policy technologies; the market, managerialism and performativity'. With complex educational reforms in the 1990s and devolvement of centralisation, markets and managers were given greater 'freedom' in relation to finance and human resource management. This changed the nature of what it was to be a teacher, both in identity and practice. The concept of performativity relates to contemporary moves to make individuals focus their practice on targets, outcomes and evaluations, which standardises and homogenises practice without taking into account the complexities of contextualised practice.

Urban (2010) and Lloyd and Hallet (2010) have also questioned how this shift in emphasis to outcome driven provision influences and impacts on early years practice and professionalism conflicting with practitioners views about their professional identity. Correspondingly, the change in status and roles of early childhood professionals and practitioners evolved and developed in response to the need for a graduate workforce, recognised by policy which developed under the New Labour government of 1997 (Lloyd and Hallet 2010). Subsequently the link between early years policy and the changing nature of professionalism at the micro level was demonstrated in Osgood's (2011) research into particular nursery contexts.

\section{Contemporary Early Childhood Policy in England}

More Great Childcare (DfE, 2013) and the Foundations for Quality (Nutbrown, DfE, 2012) were two policy documents, pertaining to Early Years provision in England and Wales. Both documents focused in particular on the nature of the early years workforce as a key component in determining 'quality' provision. The Nutbrown Review (DfE, 2012) was commissioned in response to other policy reports which highlighted that successful early intervention was dependent on high quality provision and high quality staff. The review identified disparities between similarly highly qualified staff. Both primary teachers (QTS) and early years professionals (EYP) were graduates. Staff with Qualified Teacher Status (QTS), the highest qualification for those working with children aged 3-7 years, had a career 
structure and a regulated pay-scale. However, those with Early Years Professional Status (EYPS), who had been trained to work with children aged 0-5 years, did not. They did not have a similar status recognition to those with QTS because EYP was not considered to be a qualification, nor despite sometimes being suggested as equivalent, did EYP Status, entitle the holder to the same benefits of career and pay provided by QTS status.

The Nutbrown Review (DfE 2012) proposed a solution to this disparity by the introduction of a specialist teacher for children aged 0-7 years. It was potentially a way forward for a professional route to an integrated care and education qualification that could have similar pay, status and conditions to someone with QTS. This was one of 19, generally welcomed, recommendations from the review. However, in 'More Great Childcare: Raising quality and giving parents more choice' (DfE 2013), the government's response to The Nutbrown Review, only 5 of the 19 recommendations were taken forward, and did not include the specialist teacher. In contrast to the Nutbrown Review (DfE 2012), there was an emphasis on a greater quality of choice of childcare provision for parents rather than a greater quality of the provision itself. There were several new proposals in More Great Childcare (DfE 2013), including changes to ratios of numbers of staff to children, and new structures of inspection and regulation.

Both reports stated how important it was to have a well-qualified workforce providing high quality experiences for babies and young children, in order to meet their current needs and prepare them for their futures. Whereas More Great Childcare (DfE 2013 4) concentrated on the need to build a strong professional workforce, Foundations for Quality (DfE 2012,3) emphasised the need to ensure professional and pedagogic development in order for practitioners to develop their understanding of how and why they could support and extend children's learning opportunities.

Although both documents appeared to complement each other in their vision for quality, childcare and education, it was apparent that the recommendations from Foundations for Quality (DfE 2012) were only partially addressed in More Great Childcare (DfE 2013). It also appeared that there were very differing approaches to achieving these quality initiatives.

In order to explore this seeming disconnect in more depth, this research attempted to analyse the language used within the two government publications, and explore any perceived similarities and differences. In doing so there is a resonance with the seminal work of Foucault (1972) who drew attention to the power of words as an indicator of the complex interplay between language and ideology and the power they reciprocally impart to one another. This concept has been further developed by Fairclough (1992, 3-4), who argued that:

\section{'Discourses do not just reflect or represent social entities and relations, they construct or constitute them.'}

In later and more recent expositions of his thinking, Fairclough has continued to draw specific attention to discourse analysis within the policy arena (Fairclough, 2010; Fairclough and Fairclough 2012). Critical Discourse Analysis (CDA) has been used by educational 
researchers to ask questions about relationships between language and society, specifically how these are managed in policy documents. It is worth noting that Fairclough's recent elaborations of CDA point out that the systematic and descriptive analysis of text is but part of the critical discourse analysis, which can only be truly realized in relation to wider aspects of the social processes and context. Nevertheless the systemic analysis of text can offer a useful tool to raise questions about relationships between language and society, specifically how these are managed in policy documents including educational policy (Baker 2006; Baker 2010).

The Nutbrown Review (DfE 2012) and More Great Childcare (DfE 2013) purport to have similar agendas. It is only by analysing these documents in relation to the context in which they are used that differences may emerge. Philosophical values and political agendas are not necessarily explicit but may instead be operating beneath the surface of the words and may be revealed in a more systematic analysis of texts looking at the juxtaposition and co alignment, or concordances, of words as well as the frequency or indeed absence of certain words (Baker, 2006). Close textual analysis of the two documents selected could thus offer some discrete insights in to the broader policy debates and agendas operating within the policy context of the English Early Years sector.

\section{Methodology}

A particular aim of the research was to explore underlying values and assumptions, as well as overt and covert agendas, by systematically analysing the frequency of key words in both documents in order to be able to carry out a critical discourse analysis using Fairclough's theoretical framework. The approach which was utilised is based on the work of Anthony (2013a), and Baker (2010) which identified a number of linguistic aspects that can illuminate meanings and patterns within textual analysis. These can include:

- Frequency, which ranks the frequencies with which particular words or phrases occur.

- Collocation, which identifies words that typically occur alongside one another. These may be best understood when considered alongside concordance information.

- Concordance, which lists the occurrences of particular words or terms within their immediate linguistic context. Thus it is similar to a frequency count and incorporates collocation but enables greater contextual interrogation as patterns of words and phrases can be more readily discerned.

- Keywords, which factor in lexically common words and word groupings so as to identify words that are more common than might be expected on the basis of other known texts within the field.

- Dispersion, which is the extent to which a word occurs in clusters within a corpus or is more evenly distributed.

The Antconc Tool (Anthony 2013b), is a computer programme designed to interrogate text within the parameters listed above. Drawing on extant research into discourse analysis 
techniques (Anthony 2009; Anthony 2013a) it is one of seven such tools highlighted within academic synopses of the field (Baker 2010).

For the purposes of analyzing the Nutbrown Review (NR) and More Great Childcare (MGC) the following combination of linguistic aspects were considered:

1. A simple word frequency listing was generated for each document.

2. Having generated a list of frequencies for each document, common grammatical constructs such as the definite/ indefinite article, conjunctions, prepositions etc. were excluded and the lists were scrutinized for nouns of relevance to the field of Early Years, drawing on expert opinion through the Early Childhood Studies Degree Network in the UK. This enabled the identification of a number of key thematic groupings of words that are pertinent to the field of Early Years and the policy context of the two documents under consideration.

3. Within these themes the frequency and relative ranking of usages of the selected keywords and their derivative forms were analysed to identify their respective frequency of use in NR compared to MGC and their relative ranking in order of frequency in each document.

4. For each document only words occurring in the top placed 150 words were sampled.

5. Concordances, incorporating collocation information of selected keywords, in NR and MGC were compared. Concordance plots were generated to establish that there were no unusual dispersal patterns.

6. Both documents were then compared to establish words that have particularly noticeable differential occurrences or words that do not appear as frequently as might be expected in light of the Early Childhood context.

The key ethical consideration was to take seriously the responsibility to be truthful and as objective as possible, and being objective by seeking to eliminate bias when engaged in a critique of policy documents. This was facilitated by identifying the word frequencies in each of the documents before applying an interpretation.

A simple frequency analysis of particular words excludes any contextual analysis of the sense in which these words have been utilized (Tenorio 2011) but this was mitigated to an extent by the consideration of the colocation of terms. CDA is sometimes criticised on the grounds of a lack of process between generating the frequency of words and their subsequent interpretation (Breeze 2011). This was addressed by developing a thematic grouping of frequencies within three overarching categories:

\section{Theme 1: Staff-related Terminology}


child-minder(s); experiences; knowledge; leadership; practitioner(s); professional(s) ; practice; qualification(s); qualified; skills; staff; support; teacher(s); training; understanding; workforce;

\section{Theme 2: Nature of Provision}

agency ; childminder(s); choice: flexibility; Inspection; Nursery(ies); Ofsted; Providers; provision; Quality; ratios; requirements; school(s) ; settings;

\section{Theme 3: Children Families and Development}

babies; care; childcare; child(ren);development; education; family(ies); learning; needs; parents; play.

\section{Findings}

For each of the three themes identified above the frequencies of words are presented in tables to show both the ranking of that word in the frequency tally for that document, along with the number of times it appears in the document. Although the documents are not of equal length the inclusion of the word ranking within each document indicates its relative significance within its own document and this can be compared across the documents, whereas the raw score of how many times it appears is less directly comparable. Nonetheless the raw score does give some indication of its prevalence and dispersal throughout the document within which it occurs. Exemplars of common patterns of concordances for selected keywords are then presented.

\section{Theme 1: Staff-related terminology}

\section{TABLE 1 HERE}

\section{Concordance from Theme 1: Qualifications}

From the list of staff-related terminology using word ranking and word occurrence it was possible to identify a common high ranking theme around staff qualifications in each of the documents. The following extracts are examples of the way in which this concordance was used.

\section{Nutbrown}

'We need a rigorous set of qualifications in place to ensure a competent and confident workforce'

'a worrying decline of confidence in early years qualifications and to a lowering of what we can confidently expect' 
'Dramatic growth in the number of early years qualifications from around three in 1980 to many hundreds today;'

$M G C$

'capable workforce, with more rigorous training and qualifications, led by a growing group of Early Years Teachers;'

'the quality of the workforce and the qualifications on offer at the moment are not good enough'

'exacerbated by the proliferation of early years qualifications which has occurred since the 1970s'

'many of which lack rigour and depth. We will improve early years qualifications so that parents and providers can have greater confidence'

\section{Theme 2: Nature of provision}

\section{TABLE 2 HERE}

\section{Concordance from Theme 2: Quality}

Within these word rankings it could be seen that the nominal type of provision that was foregrounded differed in the two reports. The Nutbrown Report tended to use the more generic term "settings" whereas More Great Childcare utilised language that highlighted the form of provision and tended to privilege the notion of "providers" and more frequently referred to schools, nurseries and child minders. Beyond the nominal descriptors both reports noted a focus on "quality". Therefore extracts from the documents relating to the quality of settings and provision were identified.

\section{Nutbrown}

Learning begins from birth, and high quality early education and care has the potential to make an important and positive impact on the learning, development and wellbeing of babies and young children, in their daily lives and the longer term.

Desire to give those children high quality experiences which enhance their lives and learning

$M G C$

Raising the status and quality of the workforce

Freeing high quality providers to offer more places

Expect childcare to be safe and of good quality, because high quality childcare promotes children's development in the early years

\section{Theme 3: Children Families and Development}




\section{TABLE 3 HERE}

\section{Concordance from Theme 3: Children \& Development}

It was not possible to identify collocation between all key words in the documents. Although the word babies and families generated a number of occurrences in NR, there were none in the top 150 occurrences in MGC. Conversely references to parents in MGC did not appear in the first 150 occurrences in NR. Therefore, this concordance focuses on the extracts relating to children and development.

\section{Nutbrown}

'form an understanding of each individual child, applying what they know about how children develop'

'is part of fully understanding child development and fostering independent and enquiring minds'

$M G C$

'crucial to the development of babies and young children as the foundation for their future success at school'

'by helping parents back to work and readying children for school and, eventually, employment'

\section{Summary of Concordance Themes}

Although this research only looked at aspects of concordance, the findings revealed more differences than similarities. Even where there were similarities in frequency and ranking, there were differences in context and meaning of the words. For example, in MGC (DfE 2013) the reference to staff was more aligned to leadership, whereas in the Nutbrown Review (DfE 2102) there was a greater emphasis on professionalism. Similarly, in MGC the word quality emphasised choice and availability of childcare and education (commodification), whereas the Nutbrown Review emphasised the quality of the child's experience of that care and education (experiential). The contrast between these approaches to quality could be explained by differing political and ideological viewpoints. Differing viewpoints can also be seen in the way in which children and families, and their needs are positioned. In MCG there is a focus on the standardisation and outcomes of childcare and education, of helping parents back to work, and getting children ready for school. By contrast, the Nutbrown Review focuses on the process of care and education for the child, in order to develop and foster independent and enquiring minds.

Of note within both documents was the low priority given to certain issues such as relationships, children's wellbeing, culture, diversity and special needs. For example in 
MGC, although high priority was given to school, teachers, and inspection of provision, there was no mention of babies specifically, and no reference to play as being an essential part of children's learning and development. Some of these issues of low priority in both documents will be discussed further in the next section.

\section{Discussion}

This research has demonstrated both similarities and differences of word frequencies and ranking in MGC and the Nutbrown Review using a CDA approach. On further exploration it could be seen that similar words did not necessarily have similar meanings. This was not unexpected because, from a Foucauldian perspective, although discourse can generate knowledge and truth, this type of discourse operates in powerful political and ideological systems within society which restrict how it can be interpreted (Foucault 1972). Even when there appears to be commonality

...it hides beneath what appears, and secretly duplicates it, because each discourse contains the power to say something other than what it actually says, and thus to embrace a plurality of meanings. (Foucault 1972, 118)

Discourse communicates knowledge not only about the intended meaning of the language, but also about those who put forward the discourse. Therefore, the way in which discourse is written will reflect the way in which the discourse is intended to be acted upon.

\section{Staff related terminology}

Within the first concordance theme there was a clear distinction in the way that the words related to qualifications were used. Although the words qualified and training had a similar ranking in both documents (see Table 1), the contexts of occurrences of these words were very different. Both reports recognise that there is an over proliferation of early years qualifications. However in MGC (DfE, 2013) the words qualified and training emphasised the need to have more standardised training and qualifications for the early childhood workforce. The Nutbrown Review also wanted more rigour within training but emphasised the need to have a 'confident and competent workforce' (DfE, 2012, p6) who had different levels of skills and abilities. In contrast MGC (DfE, 2013), placed a greater emphasis on the needs of parents and providers to have greater confidence in the early years workforce. The MGC (DfE, 2013) proposed that the early years workforce would be led by a group of early years teachers who would be expected to lead and take responsibility for the provision. However these early years teachers would not have the same level of pay or conditions as newly qualified teachers (NQT's).

Both documents stress the importance of having a competent workforce. A competent practitioner is viewed as someone who has a recognised qualification and experience of working with young children. This is a very broad framework because neither the specific 
qualifications are referred to, nor the length or quality of the experience. For example Nutbrown (2012) states 'We need a rigorous set of qualifications in place to ensure a competent and confident workforce' and MGC (2013) suggests the need for a 'capable workforce, with more rigorous training and qualifications, led by a growing group of Early Years Teachers'. MGC refers to the recently introduced Early Years Teacher (EYT) as leading and taking responsibility. This is not the same qualification as those who have undergone QTS teacher training. The latter has a higher status, better pay and conditions, and established support networks for professional development. An EYT would be able to work in a variety of early years settings but would not have the same status pay or conditions as a practitioner with QTS. Similarly it is less likely that someone who has Qualified Teacher Status (QTS) would be working with Foundation Stage children in early childhood settings which are organisations which aim to make a profit, where the pay and conditions may not reflect their status or expectations. This is not to say those with lower status qualifications are not competent, but the emphasis of these types of qualifications is on the functional practical role rather than the professional developmental role. Since the introduction of the EYFS settings have become more prescriptive in their approach to early childhood care and education in their attempt to meet all the required learning outcomes. This is particularly so in settings where there is top down management and little autonomy for practitioners (Silberfeld and Horsley 2013), and found to be common within bureaucratic models of leadership in which "decisions and behaviour are governed by rules and regulations rather than personal initiative' (Bush 2011, 48). In such bureaucracies Bush suggests that 'the bureaucracy itself may become the raison d'être of the organisation rather than subordinated to educational aims' (ibid, 49). Ideological differences therefore suggest that one tends towards prescriptive practice and outcome and the other towards teaching and learning as a creative and developmental process. Although both are driven by similar standards and accountability, responsibility for professional development is expressed very differently in the government documentation.

\section{Qualifications}

There is an argument within both policy documents that there are too many qualifications many of which lack the necessary rigour. Whereas Nutbrown (2012) suggests that there has been some dilution and ' $a$ worrying decline' in the confidence and competence of early years practitioners because of the range of qualifications, in MGC (2013) which is also concerned about the proliferation of qualifications, their concern is not so much with the dilution but with ensuring some mechanism of standardisation. The Nutbrown Review suggests that there is a need to ensure practitioners are qualified to a high level whereas MGC suggests that the qualifications can be improved in quality by reducing the number and standardising the content and outcomes. There is also an emphasis on improving early years qualifications 'so that parents and providers can have greater confidence' (MGC 2013, 6). This is in contrast to the Nutbrown Review which focuses on the improvement of qualifications to further prevent the 'decline' of practitioners' confidence (Nutbrown 2012, 17). 
There is an irony in governmental concerns about the proliferation of qualifications as this has come about through government policy which de-regulated early childhood qualification providers in the 1980's and has continued to be the policy of subsequent governments. Deregulation opened the market to private organisations who offered early childhood qualifications at increasingly competitive rates. Franchising became popular with many Awarding Bodies which was instrumental in the process of this proliferation. At the same time National Vocational Qualifications (NVQ), which were introduced in the late 1980s/early 1990s gave practitioners the opportunity to gain qualifications in the workplace, which would previously been inaccessible. Behind the workplace qualifications initiative was an attempt to improve the quality of provision, however the quality of the provision itself, and those who assessed the practice, differed greatly between settings.

\section{Nature of Provision}

In addition to the increase in qualifications there has also been an increase the type, range and number of early years providers, both in the state and independent sector. This has been in response to national socio-economic developments within society. It is not unusual for both parents in a family, and single parents to be working which has increased the need for childcare and education provision. This need has opened up profitable business opportunities within the childcare market. Although all settings are regulated and inspected there is no requirement for an entrepreneur to have any knowledge, understanding or skills of working with young children. There is also no impetus to employ the most highly qualified, and usually the most expensive, practitioners. Since 1997 there has been a steady increase in forprofit provision, with a 70\% increase from 2002 - 2008, which has now become the major provider for childcare of the under threes (Penn 2011). In addition $80 \%$ of all childcare and $40 \%$ of early education is now provided by this sector. Although many providers are run by individual entrepreneurs, it has been estimated by Penn (2013) that $10 \%$ of the childcare and education market is being provided by non UK based corporate companies. Lloyd (2012) suggests that this market approach encourages 'business efficiency' and a 'balance between supply and demand', whilst at the same time 'extending consumer choice'. This market approach seems to focus more on the quality of cost effective provision than quality of learning provision for the children.

\section{Quality}

The use of the word quality in both reports relates to the nature of early childhood provision. It also refers to the quality of those who work with young children. The Nutbrown Review (DfE 2012) stresses the importance of training the early years workforce in high quality settings and supported by highly qualified staff. MGC (DfE 2013) also proposed that improving the quality of the early childhood workforce was important but did not suggest how this could be achieved. The report's emphasis was that a high quality workforce would free 'high quality' providers to offer a higher number of places in settings, thus allowing a 
market solution to the increased need for available early childhood provision. Although MGC (DfE 2013) recognises that quality childcare and education promotes children's development, its emphasis on standardisation and outcome relies more on the immediacy of how the care is provided in the short term, rather than the potential for quality experiences to have a long term impact on the learning and development of the child. There is an emphasis in Nutbrown (DfE 2012) on quality provision being an investment in the child's future wellbeing which contrasts with MGC's (DfE 2013) emphasis on the economic investment. Historically the early years workforce has been predominantly female and low paid. Despite the drive in recent years towards a more highly qualified workforce, pay and conditions have not reflected these improvements (Miller 2008). Several years ago Moss (2003) put forward an interesting dilemma which may need to be addressed by future governments. He suggested that as women become better educated they may seek wider employment opportunities with better pay and conditions, rather than remaining in the early years workforce. There is nowhere within either document which considers this dilemma of gender inequity, pay and conditions.

\section{Children, Families and Development}

Within both policy documents there is acknowledgement that children's learning experiences should be of high quality. However the concept of what can be a high quality experience does not include the positioning of the child either within the family or as an individual in their own right (Lloyd 2008) or indeed what constitutes the needs of the child and whether these should be future oriented in terms of preparedness for school and eventual employability. There is also some ambivalence in both documents as to whether the needs of the child, the family or the state take precedence in the provision of childcare and education. Although there is a need to balance the interests and needs of children with the needs of the family and state, unless children experience high quality provision which meets their needs in the here and now, their 'becoming' may be adversely affected and it may affect their ability to achieve their potential.

The concepts of learning and development in the Nutbrown Review (2012) contrast with the concepts of learning and development in MGC (2013). Although both emphasise the importance of the development of, and learning experiences for, children for their long term wellbeing and readiness for school, there is a difference in perception of how this can be achieved. Nutbrown (2012) suggests that quality learning nurtures children and facilitates the development of 'independent and enquiring minds', whereas MGC (2013) suggests that quality learning is a social investment which facilitates specific learning outcomes that are the 'foundation for their future success at school'. Both suggest the need for 'schoolification' and preparation for the future (Nutbrown Review 2012, 8; MGC 2013, 4).

\section{Perceived Omissions}


In both documents there are omissions which seem striking in the context of designing quality experiences for young children. There is a lack of focus on the importance of the relationships which are developed in childhood, and how these can affect learning and development and future wellbeing. Research evidence demonstrates that children's need for emotional warmth in the early years is pivotal to their development and wellbeing (Oates 2007). Children need to form strong, mutual attachments with caregivers for their physical and emotional development. Such attachments are seen as a universal right for young children that enable them to 'construct a personal identity and acquire culturally valued skills, knowledge and behaviours' (UNCRC 2005, 8).

\section{Reflecting on the Methodology}

CDA is recognised as encompassing a hegemony of theoretical perspectives which aims to systematically investigate how power relationships ideologically shape what happens in society through practices and discourse (Fairclough 2010). It is inevitable that government policy will be influenced by political ideology, by its very nature. However, this influence may be well-hidden by the way in which policy documents are written. In both the Nutbrown Review and More Great Childcare the messages which come across highlight the importance of high quality care for young children. By systematically interrogating the language within the documents different interpretation of similar words emerged based on the frequency and context of the ways in which they were used. Although there was awareness of the need to be as objective and truthful as possible when analysing the frequencies and concordances, we were also aware that our interpretations of the discourse were influenced by our own experiences and ideologies. This has been highlighted for many years by critics of CDA who have suggested that such a method of analysing linguistic data can be used to confirm an interpretation already arrived at concerning the meaning of a text (Tenorio 2011). Fairclough (2010) has refuted these claims by his assertion that CDA is much more to do with questioning the purposes and intentions of the text, rather than the texts being interpreted in one particular ideological manner. Using Fairclough's theoretical framework we were able to explore the discourse within both policy documents, which, in turn, heightened our awareness of the complex positionality within them.

This research has raised some important questions relating to the relationship between language and political ideology in contemporary policy documents. It also gives some insight into the way in which discourse can reproduce social and political ideology.

\section{Conclusion}

There appeared to be a change of tone between the language and concepts of the Nutbrown Review (DfE 2012) and the reply of More Great Childcare (DfE 2013). This may be because those who contributed to the Nutbrown Review Foundations for Quality (DfE 2012) came from a broad range of early childhood care and education professionals and organisations, whereas More Great Childcare (DfE 2013) was written by the Department for Education, from a particular political and ideological perspective. Initially it appears that they 
have a similar vision because they have similar rationales. The rationale in Foundations for Quality as put forward by Nutbrown focuses on the need to have high quality provision because of its importance in meeting the learning needs and wellbeing of young children, which in turn will have long term consequences for their future lives (Nutbrown, DfE 2012). There was a similar rationale for More Great Childcare (DfE 2013) with the addition of affordability of provision for working parents.

However, it could be further argued that the ideological emphasis in MGC (DfE 2013) re-positions the importance of the early years by focusing on de-regulation, and the supply and demand of provision. It also opens up the market to child care providers and potentially allows them to employ less costly staff who may lack the depth and breadth of knowledge and experience of those who are more qualified which can impact on the quality of provision for children and families. Early Years teachers are not the graduate-led early childhood workforce with the parity and status of other qualified teachers within the education sector, as envisioned by those campaigning for an early years professional or pedagogue.

This research has highlighted the way in which similar words and concepts can be semantically very different, not only in the way that they are applied, but also in the way they are used politically and ideologically. Although one would expect policy documents to reflect the views, values and ideology of whichever government, individual or organisation is driving policy, the nuances of difference are not necessarily explicit. By analysing the frequency of key words in the Nutbrown Review and More Great Childcare, using the Antconc Tool, this approach to CDA has uncovered some of the differing values and assumptions which may underpin these policy documents. Whether or not this is related to different political agendas of those who wrote these documents is unclear. However, they do originate from different sources and this does seem to be reflected in the focus and tenor of the reports. Although the Government commissioned the Nutbrown Report, those who were engaged in the review did not form part of the Government. In contrast, More Great Childcare had direct Government input into the document, which reflects the Governments political agenda and in exploring perceived similarities and differences using CDA it became evident that there has been a distinct shift in the way that care and education for children has been more marketised and commodified, with an emphasis on educational outcomes rather than relational processes.

\section{Acknowledgements}

This article is based on a paper presented to the EECERA Conference (Tallinn, Aug 2013), with grateful acknowledgement of contributions from Pamela Calder, Caroline Leeson and Martin Needham of the Early Childhood Studies Degree Network in the UK. 


\section{References}

Anthony, L.2009. Issues in the Design and Development of Software Tools for Corpus Studies: The Case for Collaboration. In Contemporary Corpus Linguistics, edited by P. Baker, 87-104. London: Continuum Press.

Anthony, L. 2013a. A Critical Look at Software Tools in Corpus Linguistics. Linguistics Research 30 (2): 141-161.

Anthony, L. 2013b. AntConc 3.2.4w Programme

http://www.antlab.sci.waseda.ac.jp/antconc index.html.

Baker, P. 2006. Using Corpora in Discourse Analysis. London: Continuum International.

Baker, P. 2010. Sociolinguistics and Corpus Linguistics. Edinburgh: Edinburgh University Press.

Ball, S. J. 2003. The Teacher's Soul and the Terrors of Performativity. Journal of Education Policy 18 (2): 215-228.

Breeze, R. 2011. Critical Discourse Analysis and its Critics. Pragmatics 21 (4): 493-525.

Bush, T. 2011. Succession Planning In England: New Leaders and New Forms of Leadership. School Leadership and Management 31 (3): 181-198.

Department for Education. 2013. More Great Childcare: Raising Quality and Giving Parents More Choice. DFE-00002-2013.

https://www.gov.uk/government/uploads/system/uploads/attachment_data/file/219660/More 20Great_20Childcare_20v2.pdf.

Department for Education. 2012. The Nutbrown Review: Foundations for Quality: The Independent Review of Early Education and Childcare Qualifications. DFE-00068 2012 https://www.gov.uk/government/uploads/system/uploads/attachment_data/file/175463/Nutbr own-Review.pdf.

Elfer, P. 2007. What are Nurseries For?: The Concept of Primary Task and its Application in Differentiating Roles and Tasks in Nurseries. Journal of Early Childhood Research 5 (2): 169-188.

Fairclough, N. 1992. Discourse and Social Change. Cambridge: Polity Press.

Fairclough, N. 2010. Critical Discourse Analysis: The Critical Study of Language. Harlow: Pearson Education Ltd.

Fairclough, I., and N. Fairclough. 2012. Political Discourse Analysis. A Method for Advanced Students. London: Routledge.

Foucault, M. 1972. The Archaeology of Knowledge and Discourse on Language. London: Tavistock. 
Lloyd, E. 2008. The Interface between Childcare, Family Support and Child Poverty Strategies under New Labour: Tensions and Contradictions. Social Policy and Society 7 (4): 479-494.

Lloyd, E. 2012. The Marketization of Early Years Education and Childcare in England. In Policy Issues in the Early Years, edited by L. Miller, and D. Hevey, 107-122. London. Sage.

Lloyd, E., and E. Hallet. 2010. Professionalising the Early Childhood Workforce in England: Work in Progress or Missed Opportunity? Contemporary Issues in Early Childhood 11 (1): 75-88.

Miller, L. 2008. Developing Professionalism within a Regulatory Framework in England: Challenges and Possibilities. European Early Childhood Education Research Journal 16 (2): $255-268$.

Moss, P. 2003. Beyond Caring: The Case for Reforming the Childcare and Early Years Workforce. London: Daycare Trust.

Oates, J, ed. 2007. Attachment Relationships: Quality of Care for Young Children. Milton Keynes: Open University, and The Hague: Bernard van Leer Foundation.

Osgood, J. 2011. Narratives from the Nursery: Negotiating Professional Identities in Early Childhood. London: Routledge.

Penn, H. 2011. Gambling on the Market: The Role of For-Profit Provision in Early Childhood Education and Care. Journal of Early Childhood Research 9 (2): 150-161.

Penn, H. 2013. Childcare Markets: do they Work? In Childcare Markets: Can They Deliver an Equitable Service?, edited by E. Lloyd, and H. Penn, 19-43. Bristol: Policy Press.

Silberfeld, C.H., and K. Horsley. 2013. The Early Years Foundation Stage Curriculum in England: A Missed Opportunity?, In The Early Years Curriculum: The UK Context and Beyond, edited by L. Ang, 12-32. Harlow: Pearson.

Tenorio, E.H. 2011. Critical Discourse Analysis: An Overview. Nordic Journal of English Studies 10 (1): 183-210.

Urban, M. 2010. Rethinking Professionalism in Early Childhood: Untested Feasibilities and Critical Ecologies. Contemporary Issues in Early Childhood 11 (1): 1-7.

United Nations Committee on the Rights of the Child, United Nations Children's Fund, and Bernard Van Leer Foundation. 2005. A Guide to General Comment 7: Implementing Child Rights in Early Childhood. The Hague: Bernard Van Leer Foundation. http://www.unicef.org/earlychildhood/files/Guide_to_GC7.pdf 


\section{TABLES}

Table 1: Staff- related terminology: word ranking \& word occurrence

\begin{tabular}{|l|l|l|l|l|}
\hline \multirow{2}{*}{} & \multicolumn{2}{|l|}{ Nutbrown } & \multicolumn{2}{l|}{$\begin{array}{l}\text { More } \\
\text { Great Childcare }\end{array}$} \\
\hline Word & $\begin{array}{l}\text { Ranking in } \\
\text { document }\end{array}$ & $\begin{array}{l}\text { No. of } \\
\text { occurrences }\end{array}$ & $\begin{array}{l}\text { Ranking in } \\
\text { document }\end{array}$ & $\begin{array}{l}\text { No. of } \\
\text { occurrences }\end{array}$ \\
\hline qualification & 19 & 153 & & \\
\hline qualifications & 50 & 75 & 53 & 41 \\
\hline qualified & 79 & 50 & 76 & 29 \\
\hline training & 68 & 56 & 68 & 33 \\
\hline staff & 33 & 98 & 20 & 98 \\
\hline Practitioners & 52 & 72 & & \\
\hline Professional & 137 & 30 & & \\
\hline workforce & 75 & 51 & 140 & 18 \\
\hline childminders & & & 27 & 71 \\
\hline childminder & & & 84 & 26 \\
\hline Childminders & & & 147 & 16 \\
\hline teacher & & & 129 & 19 \\
\hline teachers & & & 130 & 19 \\
\hline practice & 58 & 62 & 144 & 17 \\
\hline support & 56 & 67 & & \\
\hline skills & 80 & 50 & & \\
\hline knowledge & 82 & 47 & & \\
\hline understanding & 88 & 43 & & \\
\hline experience & 94 & 41 & & \\
\hline leadership & 145 & 28 & & \\
\hline & & & & \\
\hline
\end{tabular}

$N B$ : where a row is blank this indicates that the word was not in the top 150 ranked words in that document 
Table 2: Nature of provision: word ranking \& word occurrence

\begin{tabular}{|c|c|c|c|c|}
\hline \multirow[b]{2}{*}{ Word } & \multicolumn{2}{|c|}{ Nutbrown Review } & \multicolumn{2}{|c|}{$\begin{array}{l}\text { More Great } \\
\text { Childcare }\end{array}$} \\
\hline & $\begin{array}{l}\text { Ranking } \\
\text { in } \\
\text { document }\end{array}$ & $\begin{array}{l}\text { No. of } \\
\text { occurrences }\end{array}$ & $\begin{array}{l}\text { Ranking in } \\
\text { document }\end{array}$ & $\begin{array}{l}\text { No. of } \\
\text { occurrences }\end{array}$ \\
\hline settings & 48 & 76 & & \\
\hline providers & & & 23 & 91 \\
\hline provision & & & 72 & 30 \\
\hline nurseries & & & 119 & 20 \\
\hline Nursery & & & 127 & 19 \\
\hline school & & & 54 & 41 \\
\hline schools & & & 77 & 29 \\
\hline agency & & & 82 & 27 \\
\hline quality & 42 & 82 & 10 & 130 \\
\hline Ofsted & & & 33 & 65 \\
\hline inspection & & & 50 & 42 \\
\hline requirements & & & 107 & 22 \\
\hline ratios & & & 61 & 38 \\
\hline France & & & 91 & 25 \\
\hline flexibility & & & 95 & 24 \\
\hline choice & & & 122 & 19 \\
\hline
\end{tabular}

$N B$ where a row is blank this indicates that word was not in the top 150 ranked words in that document 
Table 3: Children, families and development: word ranking \& word occurrence

\begin{tabular}{|c|c|c|c|c|}
\hline & Nutbrown & Review & \multicolumn{2}{|c|}{$\begin{array}{l}\text { More Great } \\
\text { Childcare }\end{array}$} \\
\hline Word & $\begin{array}{l}\text { Ranking in } \\
\text { document }\end{array}$ & $\begin{array}{l}\text { No. of } \\
\text { occurrence } \\
\text { s }\end{array}$ & $\begin{array}{l}\text { Ranking in } \\
\text { document }\end{array}$ & $\begin{array}{l}\text { No. of } \\
\text { occurrences }\end{array}$ \\
\hline children & 23 & 141 & 9 & 163 \\
\hline child & 84 & 44 & 65 & 36 \\
\hline babies & 132 & 31 & & \\
\hline families & 144 & 28 & & \\
\hline parents & & & 38 & 60 \\
\hline development & 46 & 76 & 90 & 25 \\
\hline needs & 146 & 27 & & \\
\hline education & 47 & 76 & 32 & 65 \\
\hline Education & & & 148 & 16 \\
\hline childcare & & & 37 & 62 \\
\hline care & & & 56 & 40 \\
\hline learning & 77 & 50 & & \\
\hline play & 131 & 32 & & \\
\hline
\end{tabular}

$N B$ where a row is blank this indicates that word was not in the top 150 ranked words in that document 